\title{
Modification of chicks' pecking preferences: Food imprinting or instrumental conditioning?
}

\author{
ROBERT T. BROWN \\ University of North Carolina at Wilmington, Wilmington, North Carolina 28401
}

\begin{abstract}
Using Hess' technique, 35 small groups of chicks of age 2-3 days or beyond were reinforced in training with food for pecking at one visual stimulus $(\mathrm{S}+)$ and nonreinforced for pecking at another $(\mathrm{S}-)$ and subsequently tested in extinction. In training, pecking was strongly conditioned to $\mathrm{S}+$, but in testing, both number of pecks to and preference for $S+$ declined as in instrumental conditioning, contrary to Hess' original report. Results are discussed relative to studies exposing chicks to actual food objects, where an imprinting-like phenomenon has been found.
\end{abstract}

Hess $(1964,1973)$ reported striking modification of chicks' pecking preferences under certain circumstances. At different ages, groups of 50 chicks were given one training session during which pecks to a normally nonpreferred stimulus were reinforced with food and pecks to a normally preferred stimulus were nonreinforced. On subsequent days, pecking preferences were tested in extinction. Groups reinforced when 3 or 5 days old shifted their preferences strongly-over $80 \%$ of all pecks in testing were to the previously reinforced, normally nonpreferred stimulus. However, groups reinforced when $1,2,7$, or 9 days old quickly reverted to normal preferences during testing, pecks to the reinforced stimulus being only $14 \%$ to $38 \%$ of the total pecks. Thus, there was a period labeled "critical" by Hess (1964) from age 3.5 days during which modification could occur. This period and results from drug studies led Hess to conclude that the modification of pecking preferences was a type of imprinting and was basically different from instrumental discrimination learning.

On the other hand, training similar to that used by Hess (1964) has been reported not to result in modification of pecking in small groups $(\mathrm{N}=14)$ of chicks (Meyer \& Frank, 1970). Groups reinforced for pecking at one stimulus at 1,3 , or 5 days of age all showed a rapid drop in amount of pecking in testing, although preference for the stimulus remained high in groups reinforced at 3 days. Subsequently, Frank and Meyer (1970) reported that even the preference was not modified in individually tested 3-day-old chicks, but only in groups of chicks, and concluded that the chicks' behavior resembled extinction after instrumental conditoning rather than imprinting.

This research was performed at the University of Susse $x$ while the author was a U.S.P.H.S. Postdoctoral fellow. I thank the University of Sussex for providing facilities for the research and gratefully thank Dr. R. J. Andrew for his constructive guidance and Donna Ferris for assistance in running the subjects. Also, I would like to thank Dr. E. H. Hess, whose discussion of an earlier unpublished version of this research in his recent book, Imprinting, provided the impetus for the preparation of this paper for publication.
The present paper summarizes seven experiments, with methods similar to those of Hess (1964), which showed strong conditioning of pecking to a visual stimulus but did not show persistent modification of pecking preferences of groups of 2 to 10 chicks. Training was given at the age Hess reported to be critical for modification. In an attempt to determine conditions sufficient for modification to occur, several variables were manipulated, including amount of training and size of group.

\section{METHOD}

\section{Subjects}

A total of 198 Warren sex-link chicks obtained from a hatchery at approximately $24 \mathrm{~h}$ of age $( \pm 8 \mathrm{~h})$ were the subjects. The chicks were housed in groups of 4 to 10 , depending on the experiment, in a standard chick battery where they had free access to food and water.

\section{Apparatus}

Training and testing were in 30.48-cm-square compartments, which were midgray with a hardware-cloth floor. A white stimulus panel was behind a $10 \times 14 \mathrm{~cm}$ opening in one wall of each compartment. The panels and stimuli were closely modeled after those used by Hess (1964). In the center of each pecking stimulus was either a $.64-\mathrm{cm}$ circular hole or a $.64-\mathrm{cm}$ triangular hole. Three different stimuli were used: green triangular hole (G-T), blue circular hole (B-C), and red triangular hole (R-T). Two stimuli of different colors and different-shaped holes were mounted on each panel behind $2.54-\mathrm{cm}$ holes which were $4.44 \mathrm{~cm}$ apart. Foodcups could be mounted behind a stimulus such that the subjects could obtain powdered food by pecking through the hole in the stimulus. When pecked, a stimulus closed a switch, operating a digital counter.

\section{Procedure}

Training. The chicks were given one $2-\mathrm{h}$ training session daily from 2 to 3 or more days of age. Chicks were deprived of food for $2 \mathrm{~h}$ before training and testing. Experimental (E) subjects could obtain food by pecking through the opening in one stimulus $(\mathrm{S}+)$ but not the other $(\mathrm{S}-)$. For control $(\mathrm{C})$ subjects, neither stimulus was reinforced. For convenience, the comparable color and shape stimuli will be referred to as $\mathrm{S}+$ and $\mathrm{S}-$ for both $\mathrm{E}$ and $\mathrm{C}$ subjects.

At the beginning of a session, the groups were placed in the compartments with plain white panels covering the stimulus panels. Pieces of tissue paper were placed behind the opening in 
Table 1

Training Age, Stimuli, and Size and Number of Experimental (E) and Control (C) Groups in Each Experiment

\begin{tabular}{|c|c|c|c|c|c|c|}
\hline \multirow{2}{*}{$\begin{array}{c}\text { Experi- } \\
\text { ment }\end{array}$} & \multirow{2}{*}{$\begin{array}{c}\text { Training } \\
\text { Age in } \\
\text { Days }\end{array}$} & \multicolumn{2}{|c|}{ Stimuli } & \multirow{2}{*}{$\begin{array}{l}\text { Size of } \\
\text { Group }\end{array}$} & \multicolumn{2}{|c|}{$\mathrm{N}$ of Groups } \\
\hline & & $\mathrm{S}+$ & S- & & $\mathrm{E}$ & $\mathrm{C}$ \\
\hline 1 & $2-6$ & G-T & B-C & 6 & 1 & \\
\hline 2 & $2-6$ & $G-T$ & $\mathrm{~B}-\mathrm{C}$ & 9 & 4 & \\
\hline 3 & $2-6$ & G-T & $B-C$ & 2 & 8 & 4 \\
\hline 4 & $2-6$ & G-T & $B-C$ & 2 & 2 & 2 \\
\hline \multirow[t]{2}{*}{5} & $2-4$ & $\mathrm{~B}-\mathrm{C}$ & G-T & 2 & 4 & \\
\hline & & & & 4 & 4 & \\
\hline \multirow[t]{2}{*}{6} & $2-3$ & $\mathrm{~B}-\mathrm{C}$ & R-T & 2 & 2 & 2 \\
\hline & & & & 10 & 2 & 2 \\
\hline \multirow[t]{2}{*}{7} & $2-3$ & $\mathrm{G}-\mathrm{T}$ & $B-C$ & 2 & 4 & 2 \\
\hline & & & & 10 & 4 & 2 \\
\hline
\end{tabular}

$S+$ in front of the food, and pieces of tissue-covered cardboard were placed behind the openings in $S-$ in the $E$ groups' stimulus panels and behind those in both stimuli on the $\mathrm{C}$ groups' panels. The masking panels were then raised, allowing access to the stimuli.

Each 2-h training session was divided into eight 15 min trials. Between trials, the white panels were lowered in front of the stimuli, and then the number of pecks to each stimulus was recorded, the foodcups filled, and the tissue paper replaced. The stimuli on each panel were interchanged randomly across trials.

When groups of two chicks were used, initial trials of Session 1 were conducted with at least four subjects in each group since small groups of chicks did not readily begin to peck. When the subjects began to peck, the groups were subdivided into two each for the duration of training and testing.

Testing. Two-hour testing sessions began the day after training ended. The procedure was as in training, except that pecking to neither stimulus was reinforced, tissue-covered cardboard being placed behind the hole in both stimuli. Five days of extinction testing were given.

The criterion for the pecking preferences of an $\mathrm{E}$ group to be classified as modified was that at least $80 \%$ of the pecks on each day of testing were to S+.

\section{Design of Individual Experiments}

Across the seven experiments, training varied from 2 to 3 days of age to 2 to 6 days of age, the size of each group varied 2 to 10 chicks, and different stimuli were used as $\mathrm{S}+$ and $\mathrm{S}-$.

A total of 35 experimental (E) and 14 control (C) groups was used. The number of $E$ and $C$ groups of each size in each experiment, the amount of training given, and the stimuli used are shown in Table 1.

\section{RESULTS AND DISCUSSION}

In training, pecking of all $35 \mathrm{E}$ groups was conditioned to St. Each E group emitted several thousand pecks to $S+$, with at least 5,000 pecks to $S+$ at age 3 days, and emitted relatively few pecks to $S-$. Pecking was actively conditioned to St rather than only being directed to the food itself, as shown by the results of the 1st day of testing when food was no longer present. On that day, all $\mathrm{E}$ groups continued to peck $\mathrm{S}+$ more than $\mathrm{S}-$ and pecked $\mathrm{S}+$ more than did comparable control groups. Thus, a visual stimulus associated with food rapidly gained discriminative control over the chicks' pecking.
Across the 5 test days, however, both the number and percent of pecks to $\mathrm{S}+$ declined. The number of pecks typically fell rapidly in a negative exponential function such that, by Day 5, the E groups' pecking to S+ was no higher than to $\mathrm{S}-$ and was at the level of the $\mathrm{C}$ groups. Percent of pecking to $\mathrm{S}+$ also declined, although generally more slowly, but by the end of testing was typically overlapping that of $\mathrm{C}$ groups.

The results resemble typical instrumental discrimination conditioning and extinction rather than an imprinting-like process. Food imprinting, as reflected in persistent modification of pecking preferences, was not consistently found. Only 7 of the 35 experimental groups met the $80 \%$ criterion for modification, and only two of those were responding above the level of control groups by the end of testing. Further, three of the seven groups came from one experiment, Experiment 6. Control groups in that experiment revealed that $\mathrm{S}+$ was normally strongly preferred (approximately $75 \%$ of the control groups' pecks were to St), indicating that the degree of modification in the $\mathrm{E}$ groups was actually small. The high level of pecking to S+ in training by all $\mathrm{E}$ groups indicates that the absence of persistent pecking to $\mathrm{S}+$ in testing cannot be ascribed to insufficient experience with reinforced $S+$ responding. Further, the multiple-training sessions used in these experiments should have increased food imprinting, since strength of filial imprinting varies with amount of training (e.g., Bateson, 1974; Hess, 1973).

To illustrate the general results, Experiment 7 will be presented in more detail. The results of this experiment are typical of the extent to which modification occurred or did not occur and of the wide differences between groups in modification. In Experiment 7, $\mathrm{E}$ and $\mathrm{C}$ groups of 2 or 10 chicks were trained on Days 2 and 3 of life with G-T as S+ and B-C as $\mathrm{S}-$. Figures 1 and 2 show the mean number of pecks to $S+$ and $S-$ and the mean percent of pecks to $S+$ for the experimental and control groups of 2 and 10 , respectively. As can be seen in the figures, pecking was strongly conditioned to $\mathrm{S}+$ in the $\mathrm{E}$ groups on the last day of training. The means for both number and percent of pecks to S+ accurately reflect the behavior of the individual $E$ groups-each group of 2 or 10 chicks emitted several thousand pecks at age 3 days, virtually all to St. On the 1st test day, each E group's S+ pecking was still above the level of the $\mathrm{C}$ groups, confirming that conditioning to St had occurred. Across test days, however, the number of pecks by all $\mathrm{E}$ groups declined rapidly to the level of the $\mathrm{C}$ groups. In terms of percent of pecks to $S^{+}$in testing, the results were highly variable-the mean percent of pecks for the E 2 groups was above 80 throughout testing, whereas that of $E 10$ groups fell to the level of the $\mathrm{C}$ groups. Of the individual E groups, two of the four E 2 groups and none of the four $\mathrm{E} 10$ groups met the criterion for modification. The results for all eight $\mathrm{E}$ groups combined do not meet the 
criterion for modification. Thus, when reinforced with food, pecking was conditioned to a particular visual stimulus, but when food was no longer presented, the pecking extinguished rapidly.

Looking across the seven experiments, neither size of group nor amount of training influenced preferences. Only $20 \%$ of the groups of each size met the criterion for modification: 4 of 20 groups of $N=2,1$ of 5 groups of $N=4-6$, and 2 of 10 groups of $N=9.10$. Similar trends held for amount of training: 5 of 22 groups trained on Days 2-3 or Days 2-4 of age and 2 of 13 groups trained on Days 2.6 of life showed modification.

A relation which may held to account for the degree of modification in testing is that between percent of pecking to $\mathrm{S}+$ in training and that in testing. Most responses by all $\mathrm{E}$ groups in training were to $\mathrm{S}+$, but the percent of $\mathrm{S}+$ responses ranged from 79.1 to 100.0. In testing, the percent of $S+$ responses ranged from 42.9 to 98.7. Using a Spearman rank-order correlation, the percent of S+ responses in training was correlated with that in testing for the $27 \mathrm{E}$ groups for which all data were available. (Training data on at least 1 day were lost for eight $\mathrm{E}$ groups through equipment failure.) The resulting correlation of .67 is highly significant $(\mathrm{p}<.001)$. For the $21 \mathrm{E}$ groups whose percent of $\mathrm{S}+$ responses in training was over 96 , the correlation is nearly as high--.61 $(\mathrm{p}<.01)$. Thus, even relatively small amounts of $S-$ pecking in training were related to $S$ pecking in testing. Variability in $\mathrm{S}$ - responding in training presumably stemmed from individual differences in preference for the stimuli, as indicated by wide variability in pecking by the $C$ groups.

In the experiments reported here, both the number and percent of pecks to St fell rapidly in testing, resembling extinction after instrumental conditioning
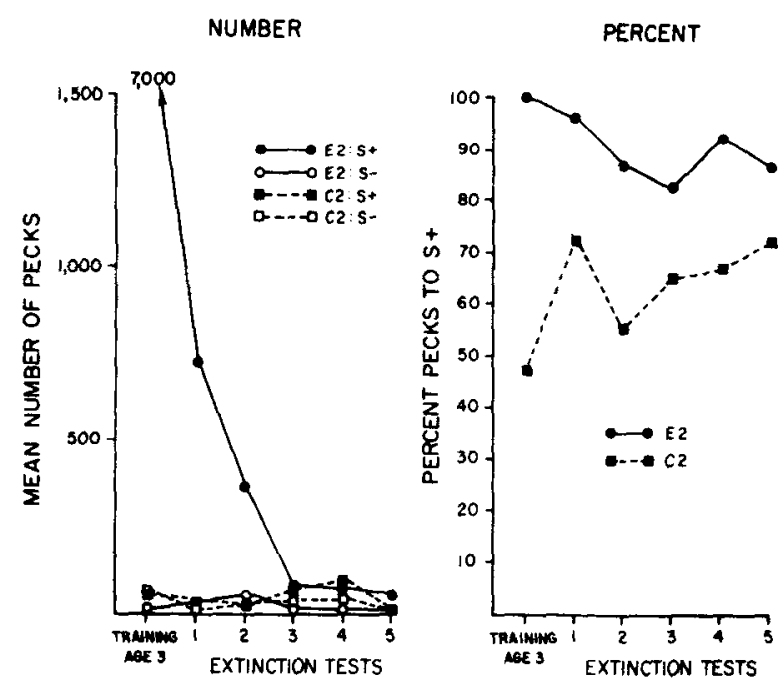

Figure 1. Mean number of pecks to each stimulus and mean percent of pecks to $S+$ on the last training session and exch testing session for experimental (E) and control (C) groups of 2 chicks each.
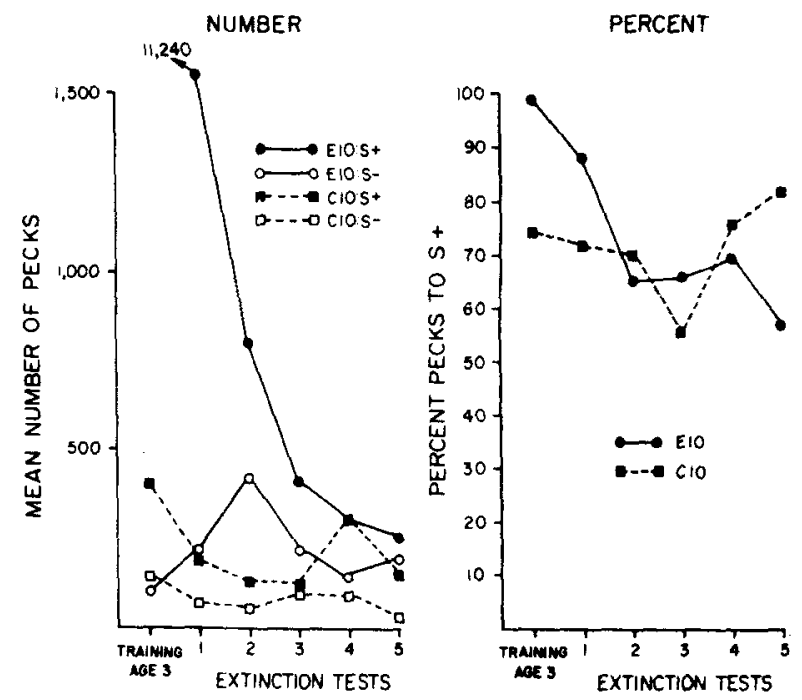

Figure 2. Mean number of pecks to each stimulus and mean percent of pecks to $S+$ on the last training session and each testing session for experimental (E) and control (C) groups of 10 chicks each.

rather than an imprinting-like process. Meyer and Frank (1970) and Frank and Meyer (1970) reported results similar to those in the present experiments, except that in their studies, percent of pecking to S+ remained high in testing for groups of three or four chicks but fell rapidly for individual or paired chicks. As suggested by Meyer and Frank (1970) and Frank and Meyer (1970), results of pecking-preference studies using groups of chicks may be influenced by social facilitation (e.g., Tolman, 1964), through which a chick's pecking is influenced by the pecking of other chicks. In a group of chicks, social facilitation can become a positive feedback loop-one chick's pecks evoke pecks from other chicks, which in turn evoke further pecks from the first chick. Such facilitation was observed informally in the present experiments when, during training and testing, a peck by one chick to either stimulus evoked a flurry of pecks to the same stimulus by other chicks.

A number of procedural differences between the present studies and those of Hess may account for the different extent to which modification of preferences was obtained. Hess used groups of 50 chicks in a large octagonal apparatus containing eight pairs of stimuli. The larger groups and number of stimuli used by Hess may have resulted in some chicks having very high response rates to $S+$ which led to persistent modification in those subjects. That is, the persistent modification may have been a function of very high pecking to $S+$ by a small number of the 50 chicks. If there are large individual differences between chicks in the extent to which preferences are modified, then it would be more probable that some chicks in a group of 50 would show modification than in a smaller group. A second difference is that Hess (Note 1) deprived his chicks of food for 6 to $8 \mathrm{~h}$ before training, whereas only $2 \mathrm{~h}$ of 
deprivation was used in the present experiments. The higher deprivation used by Hess may have affected both the rate and intensity of response to St. Lastly, it should be mentioned that the breeds of chick differed across the two sets of experiments, and different lines of chick vary considerably in their behavior in imprinting situations. The particular reason why modification has been consistently obtained using large groups and large numbers of stimuli (Hess, Note 1) and only erratically under conditions using smaller groups remains a puzzle.

In any event, rapid and strong conditioning of chicks' pecking to a visual stimulus associated with food has been consistently found, but persistent modification is an elusive phenomenon, at least in small groups of chicks. It appears that a visual stimulus paired with food comes to function through conditioning as a discriminative stimulus, with pecking extinguishing when food is no longer presented.

When actual foods have been used, however, strong preferences have been established or modified in young organisms. Both chicks (Burghardt, 1969; Capretta, 1969) and snapping turtles (Burghardt, 1967; Burghardt \& Hess, 1966) prefer the food fed first after hatching to one fed subsequently, suggesting a primacy effect, and the preferences induced by first feeding may persist in chicks (Capretta, 1969). Further, in his detailed analysis of the development of chicks' recognition of food, Hogan (1973) found that ingestion of a food by chicks less than $72 \mathrm{~h}$ old did not increase their subsequent pecking to that food, whereas ingestion of the same amount of food by 72-h-old chicks greatly increased their subsequent pecking. As Hogan states, the sharp age relation suggests the onset of a critical period for establishment of food objects, supporting Hess' original contention.

Considered from the standpoint of the chick's adaptation to its environment, the transitory effects of manipulating stimuli associated with food are not surprising. A chick which associates a visual stimulus with food objects is learning where food is located, not what food is. If food becomes no longer available at a particular place, it would be maladaptive to continue pecking at that place instead of moving to a different place. On the other hand, rapid and persistent learning of what are appropriate food objects would be clearly adaptive for young precocial animals which begin to obtain their own food at or shortly after hatching or birth. As Hess (1973) has recently noted, there may be great differences between the effects of signals for food and food itself.

\section{REFERENCE NOTE}

1. Hess, personal communication, 1974.

\section{REFERENCES}

Bateson, P. P. Length of training, opportunities for comparison, and imprinting in chicks. Journal of Comparative and Phy siological Psychology, 1974, 86, 586-589.

Burghardt, G. M. The primacy effect of the first feeding experience in the snapping turtle. Psy chonomic Science, 1967, 7, 383-384.

Burghardt, G. M. Effects of early experience on food preference in chicks. Psy chonomic Science, 1969, 14, 7-8.

Burghardt, G. M., \& Hess, E. H. Food imprinting in the snapping turtle, Chelydra serpentina. Science, 1966, 151, 108-109.

Capretta, P. J. The establishment of food preferences in chicks Gallus gallus. Animal Behaviour, 1969, 17, 229-231.

Frank, L. H., \& Meyer, M. E. Food imprinting in domestic chicks as a function of social contact and number of companions. Psychonomic Science, 1970, 19, 293-295.

Hess, E. H. Imprinting in birds. Science, 1964, 146, 1128-1139.

Hess, E. H. Imprinting. New York: Van Nostrand, 1973.

Hogan, J. A. Development of food recognition in young chicks: I. Maturation and nutrition. Journal of Comparative and Physiologicai Psy chology, 1973, 83, 355-366.

Meyer, M. E., \& Frank, L. H. Food imprinting in the domestic chick: A reconsideration. Psychonomic Science, 1970, 19. 43-45.

Tolman, C. W. Social facilitation of feeding behaviour in the domestic chick, Animal Behaviour, 1964, 12 , 245-251.

(Received for publication July 15,1974 ; revision accepted January 27,1975 .) 